PREPARED FOR THE U.S. DEPARTMENT OF ENERGY, UNDER CONTRACT DE-AC02-76CH03073

PPPL-3738

PPPL-3738

UC-70

Investigations of Probe Induced Perturbations in a Hall Thruster

by

D. Staack, Y. Raitses, and N.J. Fisch

August 2002

$\left.\stackrel{M}{M}\right|_{\substack{\text { PRInCETON PLASIMA } \\ \text { PHYSICS LABORATORY }}} ^{D}$

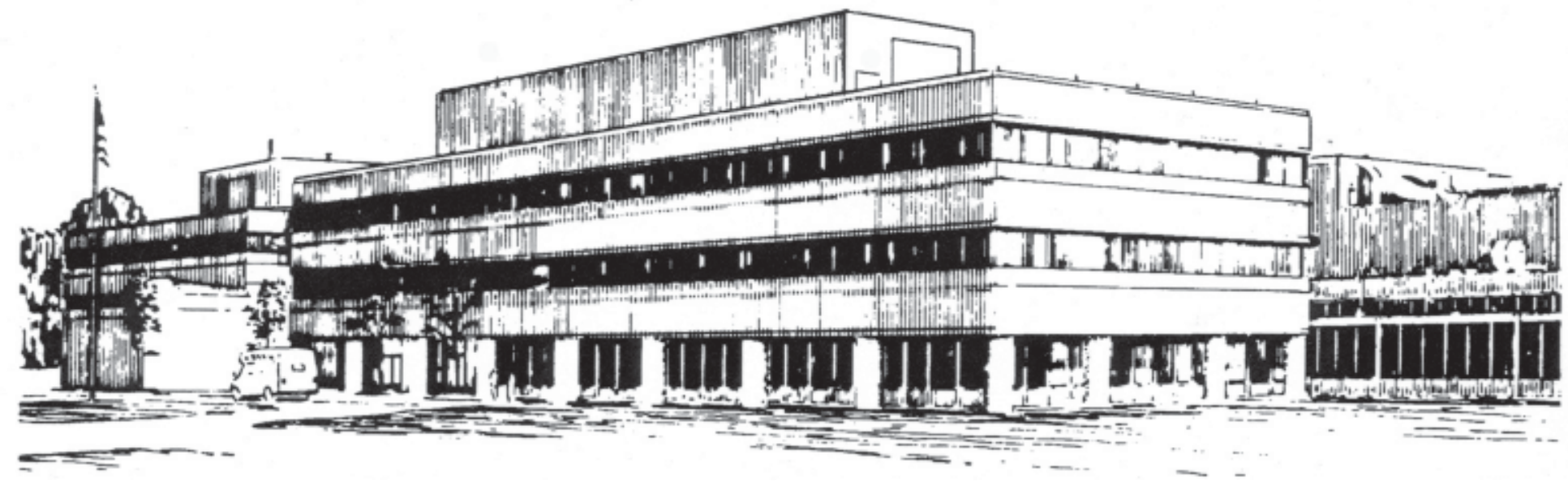

PRINCETON PLASMA PHYSICS LABORATORY PRINCETON UNIVERSITY, PRINCETON, NEW JERSEY 


\section{PPPL Reports Disclaimer}

This report was prepared as an account of work sponsored by an agency of the United States Government. Neither the United States Government nor any agency thereof, nor any of their employees, makes any warranty, express or implied, or assumes any legal liability or responsibility for the accuracy, completeness, or usefulness of any information, apparatus, product, or process disclosed, or represents that its use would not infringe privately owned rights. Reference herein to any specific commercial product, process, or service by trade name, trademark, manufacturer, or otherwise, does not necessarily constitute or imply its endorsement, recommendation, or favoring by the United States Government or any agency thereof. The views and opinions of authors expressed herein do not necessarily state or reflect those of the United States Government or any agency thereof.

\section{Availability}

This report is posted on the U.S. Department of Energy's Princeton Plasma Physics Laboratory Publications and Reports web site in Fiscal Year 2002. The home page for PPPL Reports and Publications is: http://www.pppl.gov/pub_report/

DOE and DOE Contractors can obtain copies of this report from:

U.S. Department of Energy

Office of Scientific and Technical Information

DOE Technical Information Services (DTIS)

P.O. Box 62

Oak Ridge, TN 37831

Telephone: (865) 576-8401

Fax: (865) 576-5728

Email: reports@adonis.osti.gov

This report is available to the general public from:

National Technical Information Service

U.S. Department of Commerce

5285 Port Royal Road

Springfield, VA 22161

Telephone: $1-800-553-6847$ or

(703) $605-6000$

Fax: (703) 321-8547

Internet: http://www.ntis.gov/ordering.htm 


\title{
Investigations of Probe Induced Perturbations in a Hall Thruster
}

\author{
AIAA 2002-4109 \\ D. Staack, Y. Raitses and N. J. Fisch \\ Princeton Plasma Physics Laboratory, Princeton, NJ, 08540
}

\begin{abstract}
An electrostatic probe used to measure spatial plasma parameters in a Hall thruster generates perturbations of the plasma. These perturbations are examined by varying the probe material, penetration distance, residence time and the nominal thruster conditions. The study leads us to recommendations for probe design and thruster operating conditions to reduce discharge perturbations, including metal shielding of the probe insulator and operation of the thruster at lower densities.
\end{abstract}

\section{Introduction}

A conventional Hall thruster is a crossed field electric discharge device with a coaxial channel, in which the electrostatic acceleration of ions takes place in a quasi-neutral plasma. A significant axial electric field is established in the vicinity of the maximum radial magnetic field near the thruster exit plane. The magnetic field surfaces in the acceleration region are essentially equipotential except for electron pressure effects. $^{1}$

Probe measurements of the plasma potential, electron temperature, and plasma density, are one vital means to understanding the physics within the acceleration region of a Hall thruster. However, introducing probes into the acceleration region has caused significant perturbations to the Hall Thruster discharge, namely increases up to and greater than $50 \%$ and fluctuations of the discharge current. ${ }^{2,3,4}$ Ion velocity measurements using LIF are nonintrusive and informative but the breadth of the ion creation region leads to uncertainties in determining the electric field from those measurements. ${ }^{5}$

Copyrights (c) 2002 American Institute of Aeronautics and Astronautics Inc. All rights reserved
Hass et al. ${ }^{4}$ performed an experimental study of the perturbations induced by probe and supported their results with a probe thermal model taking into account heating and probe ablation by the electron Hall current. The main conclusions were that probe ablation causes perturbations that can be avoided by fast reciprocating probes. Indeed For a $5 \mathrm{~kW}$ Hall thruster the use of the fast reciprocating system was sufficient to bring discharge current perturbations down to less than $10 \%$ of the discharge current. ${ }^{4}$ However, the use of a fast reciprocating probe did not sufficiently ameliorate the probe-induced perturbation in recent experiments on the smaller sized PPPL Hall Thruster ${ }^{2}$.

This study contains a further examination into the causes and effects of the perturbations by varying the thruster conditions, material and construction of the probe, and parameters of insertion. The magnitude and nature of the perturbations are shown to depend on all these variables.

\section{Experimental Setup and Procedure}

The $9 \mathrm{~cm}$ laboratory Hall thruster and test facility used in this study has been described in previous works. ${ }^{6,7}$ Fig. 1 shows this thruster with the high speed probe mounted on a movable positioning system and azimuthally located stationary probes at approximately $1 \mathrm{~mm}$ from the exit plane. The high-speed diagnostic probe is mounted on a radial and axial positioning system. The axial position is controlled by a fast Normag linear motor with a maximum speed of $1.5 \mathrm{~m} / \mathrm{s}$ and a maximum acceleration of approximately $1 \mathrm{~g}\left(10 \mathrm{~m} / \mathrm{s}^{2}\right)$. The axial position is measured with a resolution of $20 \mu \mathrm{m}$ using a Renishaw optical encoder. A relatively slow Velmex linear gear motor controls the radial position. 


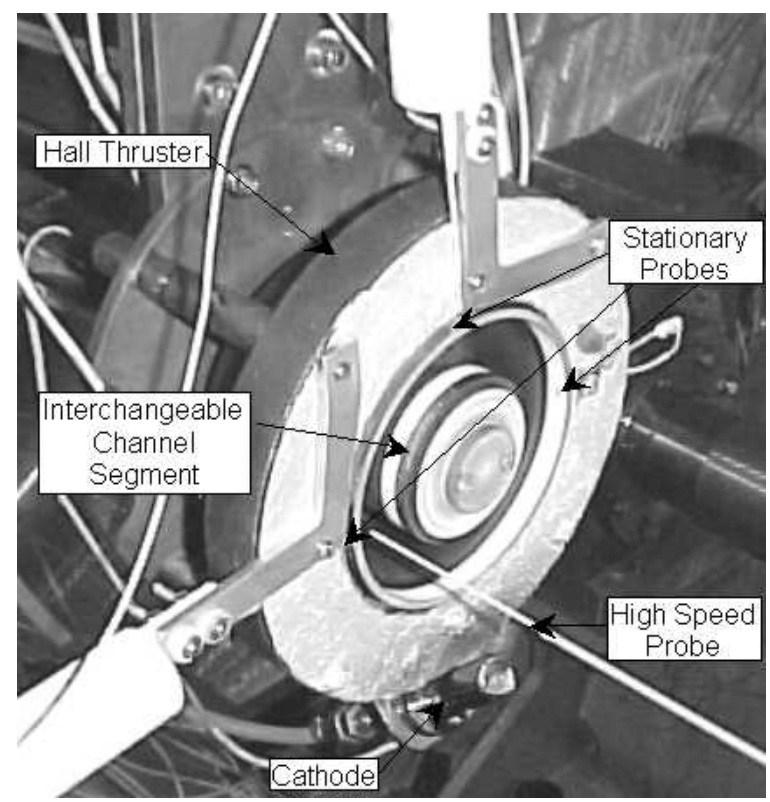

Figure 1: PPPL 9cm Hall thruster with stationary and high-speed probes.

Using the positioning system the probeinduced perturbations were characterized as a function of: the radial position of insertion, $R$, measured from the annular channel median, the depth of insertion into the channel $\mathrm{D}$, measured from the probe exit plane, the speed of the probe $\mathrm{V}$, the residence time of the probe within the thruster T, and TW the wait time at the nearest position. Fig. 2 is a typical position versus time plot of the probe showing some of these variables.

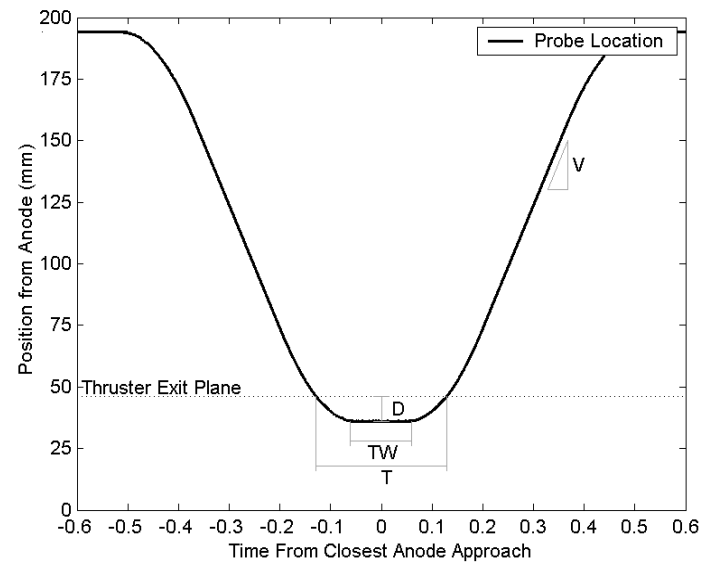

Figure 2: Plot of probe position and insertion variables.

The primary parameter of the thruster discharge operation measured was the discharge current. The perturbations where characterized by changes in the measured discharge current during the insertion of the probe. The effect of these perturbations on the potential distribution within the thruster was also studied. First, by using the potential measured by the inserted probe, and second by measuring the floating potentials of three fixed Langmuir probes at different azimuthal locations along the outer channel wall near the thruster exit (Fig. 1). Control of the positioning system and the signal measurements were performed by a National Instruments, PC-based, data acquisition system.

The geometry of the inserted probe is given in Fig. 3. This geometry was also used in our previous works. ${ }^{2}$ The probe consists of a is a high purity alumina double bore tube $1.1 \mathrm{~mm}$ in diameter. The probe leads, and tip are made from $0.25 \mathrm{~mm}$ diameter thoriated tungsten with the filament tip electrolytically etched to $0.11 \mathrm{~mm}$ in diameter. The probe shield is a $0.35 \mathrm{~mm}$ thick molybdenum tube that fits tightly over the alumina tube; it strengthens the probe and improves axial heat conduction. A thin boron nitride coating insulates the probe shield from the surrounding plasma. The use of the shield caused no changes in the performance of or disturbances from the probe other than to increase probe longevity. The overall probe length (L) varied from 200 to $250 \mathrm{~mm}$. This nominal configuration was modified in several ways to study the source of the perturbations. The probe was operated with a heated emissive tip, with the tip cold and with the wires removed. Additionally two other materials were tested in place of the alumina tube: a fused quartz tube with no wires, and a tungsten rod.

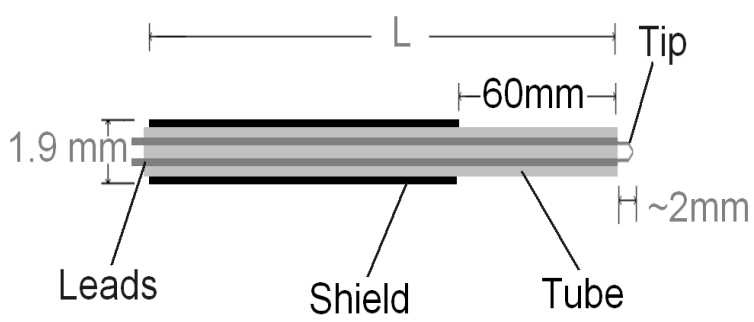

Figure 3: Geometry of Probe 


\section{Experimental Results}

Figure 4 shows the discharge current measured during a typical insertion of the probe during emissive probe measurements. The thruster was operating without segmented electrodes at $250 \mathrm{~V}$ and a mass flow rate of 1.7 $\mathrm{mg} / \mathrm{s}$ of Xenon. Figure 4 shows the discharge current as a function of time, and as a function of position; $\mathrm{t}=0$ and $\mathrm{z}=0$ are taken at the first crossing of the thruster exit plane. The discharge current begins increasing about $5 \mathrm{~mm}$ outside the thruster until about $4 \mathrm{~mm}$ inside the thruster, where the average value of the discharge current saturates but large amplitude oscillations begin. The oscillations were measured to be in the range of 15 to $20 \mathrm{kHz}$ for the emissive and tungsten probe. The average discharge current increased to $150 \%$ of the unperturbed value. It is possible to divide the effect the probe on the discharge current perturbation into two phases the initial, growing phase where the discharge current increases and the oscillatory phase where the discharge current oscillates.

The discharge current perturbations induced by the probe were repeatable for the emissive probe in terms of their average value and maximum amplitudes. Prior to the oscillatory phase the standard deviation of the discharge current over 10 probe insertions was less than $5 \%$. However when oscillations began the variation was large due to the nature of the disturbance. Nevertheless, for averaged values of the discharge current and the amplitude of the oscillations the error was less than $15 \%$. The measured plasma potential and stationary probe potential had similar repeatability dependent on the location of the probe inside the thruster.

For different $\mathrm{D}, \mathrm{T}, \mathrm{TW}, \mathrm{V}$, and the same $\mathrm{R}$ the perturbations were repeatable as a function of the position of the probe not the amount of time the probe was in the thruster as was suggested by ref. 4. The transition from the growing phase to oscillatory phase is also a function of the position of the probe, and cannot be considered as a function of the perturbed discharge current since at different radial locations the transition began at different perturbed discharge currents.
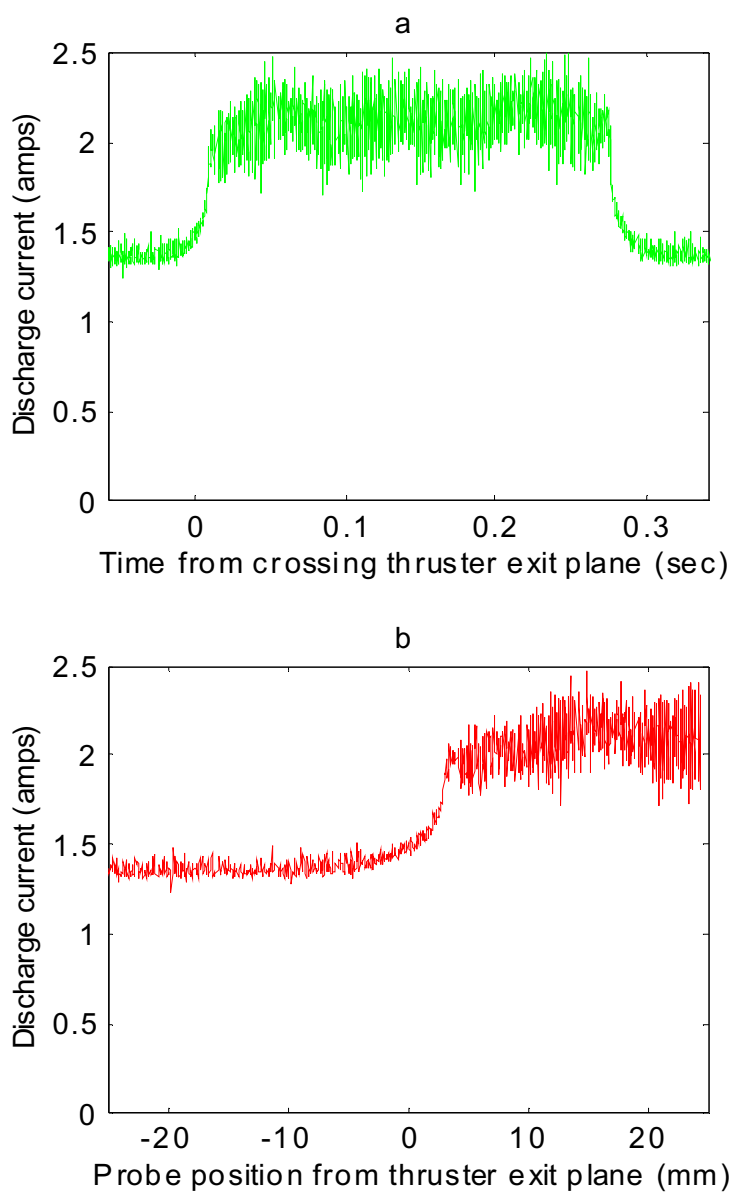

Figure 4: Discharge current perturbations as a functions of (a) time and (b) position (inward portion of insertion only, to $\mathrm{t}=141 \mathrm{~ms}$ ).

To verify this observation the probe was inserted into the thruster at three different penetration depths 3, 4, and $5 \mathrm{~mm}$. The discharge current and position of the probe as a function of time from crossing the exit plane are plotted in Fig. 5. This experiment was done using the alumina probe with no probe wire at the outer wall of the thruster. For 3 and $4 \mathrm{~mm}$ penetrations the oscillatory perturbations did not occur. However, a non-oscillatory perturbation did occur at these penetrations but only after a prolonged exposure to the plasma. Examination of the probe, after long duration experiments, revealed melting localized to only the side of the probe facing the azimuthally drifting electron this result is similar to that of ref. 4 . For the 5 $\mathrm{mm}$ penetration the discharge current oscillations were excited almost instantaneously and no melting was visible. Additional submillimeter changes in $\mathrm{D}$ showed the boundary 
between the perturbation phases to lie between 4.5 and $4.8 \mathrm{~mm}$ inside the thruster and the oscillations to be activated within $0.5 \mathrm{~ms}$.
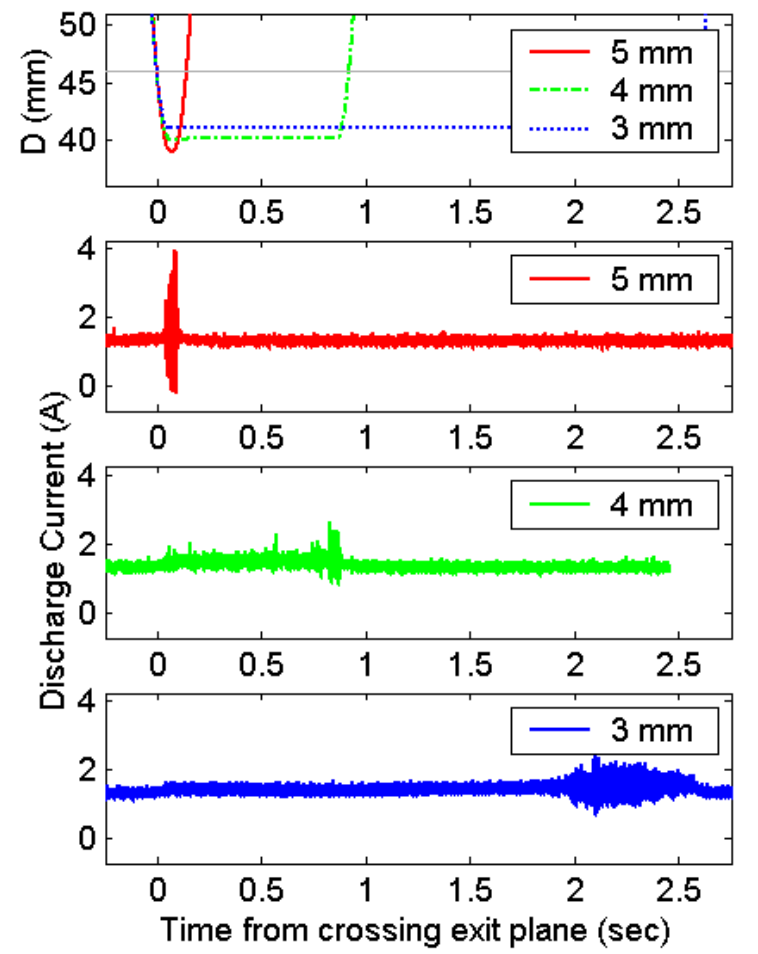

Figure 5: Discharge current perturbations at 3, 4, and $5 \mathrm{~mm}$ penetrations.

Variations of these oscillations with the radial position of the probe are shown in Fig. 6 . Interestingly there is an inverse relationship between the amplitude of the oscillations and the change in current, this was also apparent for other probes. The specific boundary between the perturbation phases is shown in figure 6c.

Fig. 7 shows the averaged discharge current profiles as a function of the position of the end of the probe tube for various probe configurations. All probes experienced growing and oscillatory phases of the perturbation with a specific location marking the transition. For the hot emitting probe the discharge current increases sooner and the induced oscillations begin sooner. In comparison of the cold probe to the probe with no wire we see a similar discharge current growth phase and transition location but the mean value about which the oscillations occur is much lower when there is no probe wire, also the amplitude of the oscillations were greatest for the case with no probe wire.

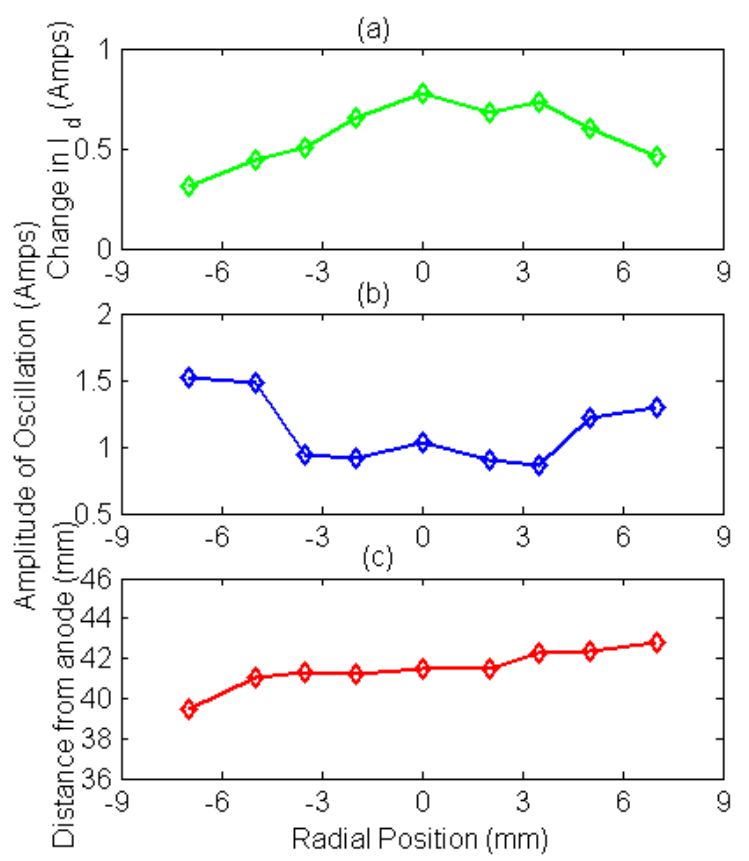

Figure 6: Radial variation of (a) change in average value of discharge current (b) amplitude of discharge current oscillations and (c) the location where the perturbation transitions from growing to oscillatory. The thruster exit plane is located $46 \mathrm{~mm}$ from the anode and the channel is $18 \mathrm{~mm}$ wide.

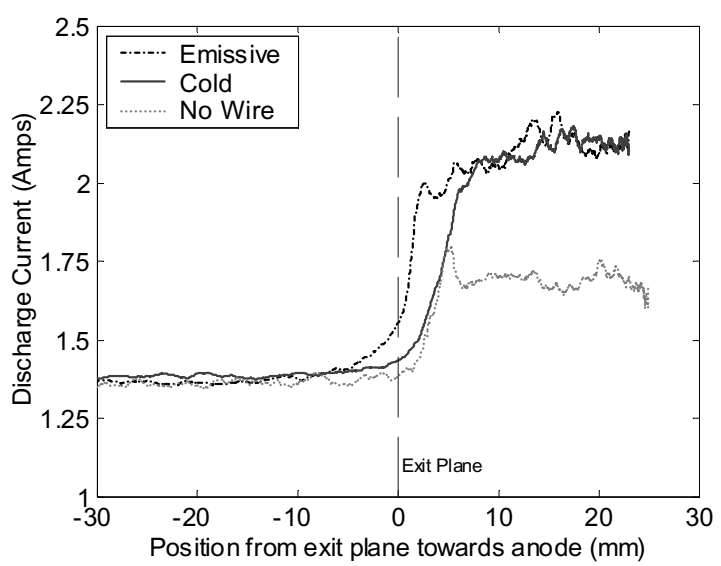

Figure 7: Discharge current perturbations for alumina emissive, cold, without wire configurations.

The discharge current as the alumina, tungsten, and quartz probes are inserted $25 \mathrm{~mm}$ into the thruster near the outer wall is shown in Fig. 8. Fig. 9 shows the discharge current as a function of position of the different probes as they are inserted at the middle channel. The discharge current is averaged over the oscillation period and several probe insertions. The stars on the plots indicate where the large amplitude 
oscillations began. Quartz causes the largest changes in discharge current, alumina less and tungsten significantly less. Both alumina and tungsten probes cause the instabilities. They both caused it at approximately the same location in the thruster. Note that, large amplitude burst-type perturbations, measured for quartz tube, are not oscillatory in nature. There was no locational sensitivity to these bursts; and melting of the quartz was visible upon examination of the quartz probe after use.

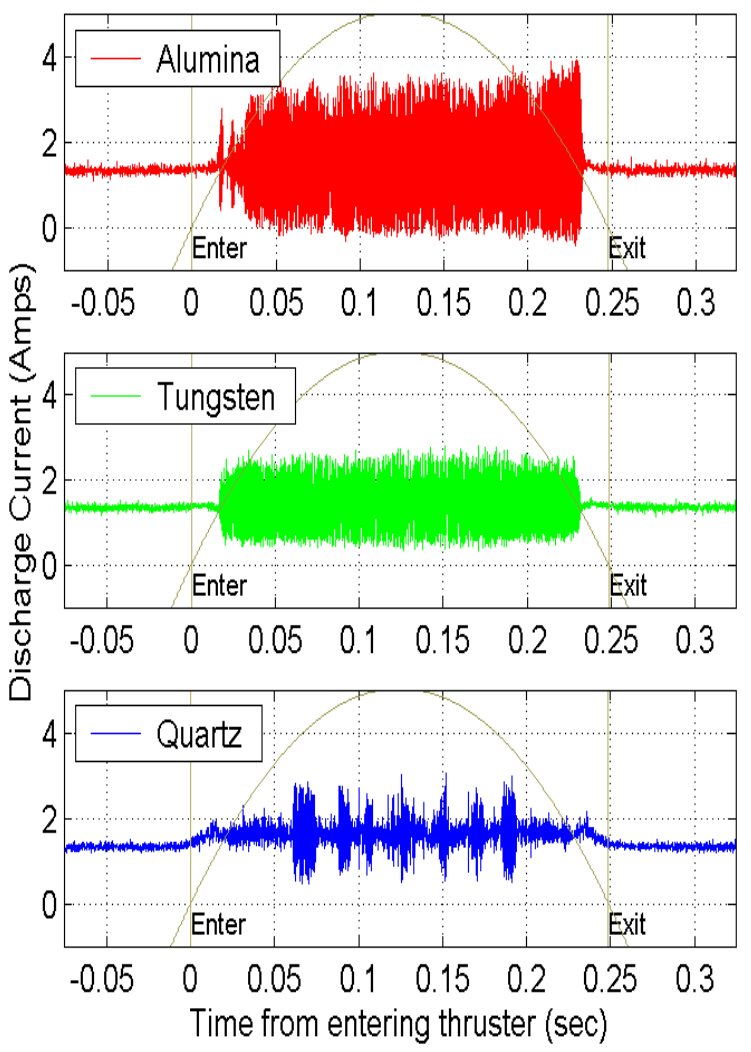

Figure 8: Discharge current perturbations caused by an (a) alumina, (b) tungsten, and (c) quartz probe body as a function of time.

For alumina, tungsten, and quartz materials tested Fig. 10 shows the change in the stationary probe voltage for two azimuthal locations when the probe is inserted in the middle of the channel. The changes induced by the tungsten probe appear to be azimuthally symmetric while those for the dielectric probes have strong asymmetries. For other radial insertions and the third azimuthal probe the trends were the same.

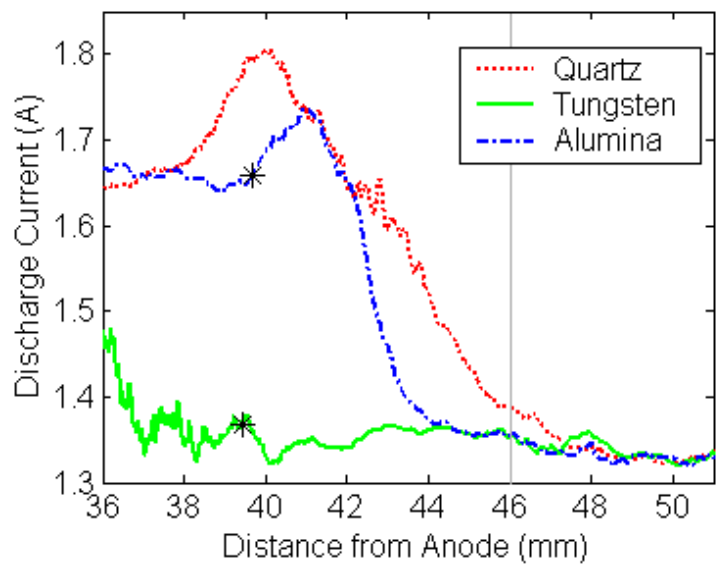

Figure 9: Discharge current perturbations caused by alumina, tungsten, and quartz probes at the middle of channel as a function of the position of the probe.

(a) - Near Insertion

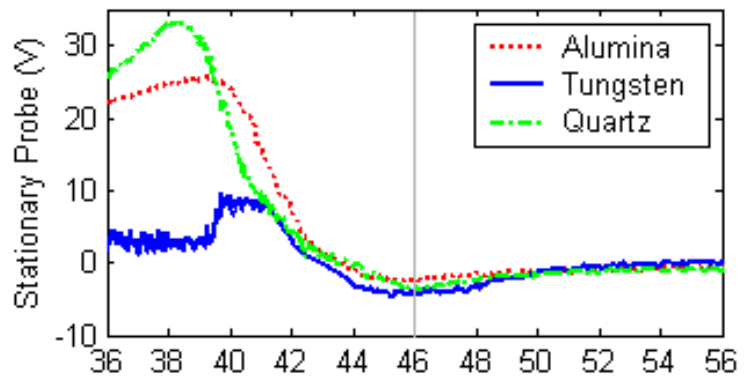

(b) - Opposite Insertion

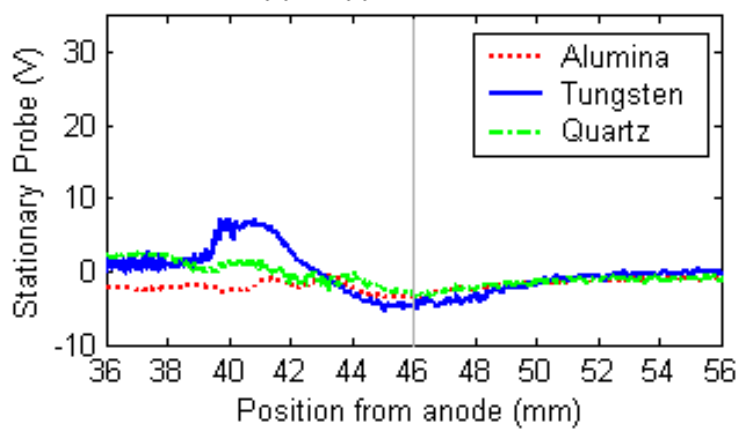

Figure 10: Changes to stationary probe voltage located (a) near the point of insertion and (b) opposite the point of insertion for three probe body materials.

Conversely to the probe causing oscillatory perturbations, for initially unstable thruster operation the probe insertion caused a decrease in oscillations. Fig. 11 shows the discharge current as a function of emissive probe position at different external and internal coil currents but the same voltage as those in Fig. 4. As seen in Fig. 11a when the probe is outside the thruster the discharge current is plagued by large 
amplitude oscillations, over a certain range of locations within the thruster the presence of the probe is able to decrease these oscillations. When the thruster was operated with a MACOR spacer (Fig. 11b) not such oscillations were present.

(a) Boron Nitride $(0.45,2.25)$

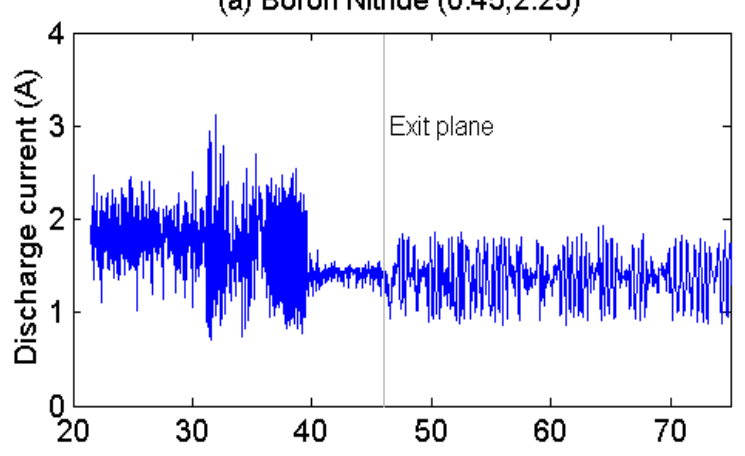

(b) Macor $(0.45,2.25)$

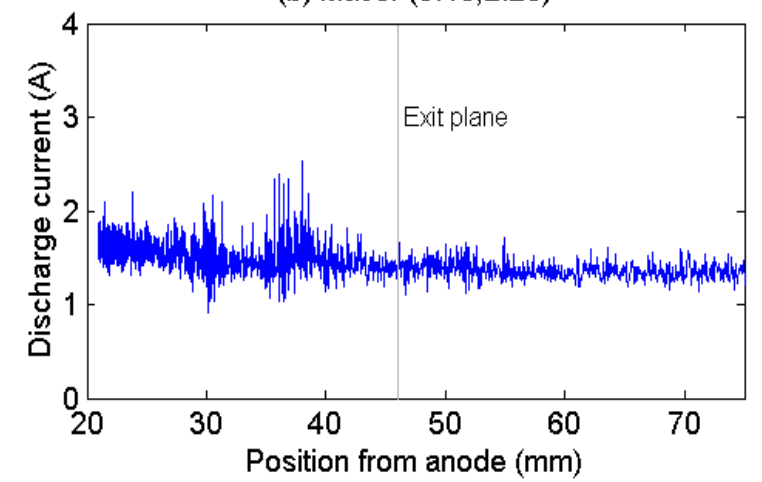

Figure 11: Discharge current perturbation at different coil currents with the introduction of an emissive probe; (a) not channel segments, (b) MACOR channel segment.

\section{Discussion}

Ablation is seen to be a cause for nonoscillatory disturbances but only if the probe is left in the thruster for a sufficient amount of time (Fig. 5). The times after which the disturbance occurred, about $.7 \mathrm{sec}$ for $4 \mathrm{~mm}$ and 1.9 seconds for $3 \mathrm{~mm}$ penetrations. For the insertion of quartz in figure $8 \mathrm{c}$ ablation occurs after $80 \mathrm{~ms}$. These results are consistent with the ablation model of Ref. 4 and reaffirm the need for fast movable probes.

For the oscillatory perturbations it is unlikely that ablation is a source. Ablation would have to occur within the $0.5 \mathrm{~ms}$ in which the large amplitude oscillations begin. A calculation using the ablation model predicts ablation times of this order only for electric fields over five times in excess of those measured. Shorter ablation times could be predicted adding secondary electron emission (SEE) into the ablation model of Ref. 4. In this model the heat flux due to the random flux of electrons to the probe was essentially neglected because of a large negative sheath between the plasma and probe. SEE can affect this sheath and increases the heat flux to the probe. When the SEE coefficient is near unity two solutions for the sheath have been found ${ }^{8}$, a positive sheath and a double sheath. For a positive sheath the heat flux grows significantly. Modifications to the ablation model show that it is possible that this boundary where the perturbations become oscillatory (Fig. 6c) corresponds to the point where the electron energy reaches the first SEE threshold, around $25 \mathrm{eV}$ for alumina ${ }^{9}$. The formation of a double sheath however appears to be a more consistent ${ }^{10}$ solution than a positive sheath. The double sheath limits the heat flux to at most on the order of the heat flux with zero sheath potential affecting the electrons. With these modifications the ablation model still predicts ablation times over an order of magnitude greater than the time scales of the oscillation activation. Ablation therefore probably is not the cause of the large amplitude oscillatory perturbation to the discharge current.

Furthermore the tungsten probe results rules out ablation as a cause for the oscillatory perturbations. Variations in the penetration distance performed for the tungsten probe, similar to alumina, revealed the existence of the same type of boundary where the oscillations began. Taking into account that tungsten has a larger melting temperature and lower SEE than alumina, the probability of ablation for the tungsten probe inside the thruster is unlikely. Nevertheless, the induced oscillatory behavior for both alumina and tungsten are similar in nature. Remarkably the maximum duration for tungsten left $1 / 2 \mathrm{~mm}$ downstream of the boundary was 13 seconds without any changes in the disturbances.

Note that these oscillatory perturbations are only excited when the tungsten, emissive, cold and no-wire probes cross a specific boundary in the thruster similar to that in Fig 6c. For the quartz probe oscillation were not measured. The 
results for alumina at the inner wall also indicate that in addition to crossing the specific boundary a minimum increase in discharge current is also required to incite perturbations. Though these oscillations are not understood some mechanism for oscillations may arise from changes in the relative contributions of near wall conductivity and Bohm diffusion to the electron transport. ${ }^{11}$ The inserted probe may cause an increase in axial conductivity, as is evident by the increase in discharge current prior to the onset of oscillations.

The ability of the probe to change the thruster operating regime seen in Fig. 11 is very similar to the effect of passive segmented electrodes $^{12}$. The perturbations caused by the probe change the dynamics of the thruster and so change the stability of the thruster at these operating conditions.

The discharge current perturbations during the growing phase are critical since they affect important regions of interest. The increase in the discharge current seen was as much as 0.7 amps $(50 \%)$ even prior to the activation of instabilities. This suggests that even if the thruster can be operated in a regime with no instabilities discharge current perturbation may still be significant enough to bring measurements into question. It should be noted that although in Ref. 4 perturbations were reduced to less than $10 \%$ of the discharge current the magnitude of the perturbation was still around 1 amp. It seems that for larger thruster and larger mass flow rate there is a proportional decrease in the discharge current not an absolute one. Considering that the size of the probes used by Ref. 2, 4, 5 are approximately the same the fact that the changes in the discharge current are roughly the same absolute magnitude suggest a similar nature of these perturbations in different Hall thrusters of different sizes.

Plasma losses to the probe are one way in which the probe might increase the discharge current. A simple analysis comparing the surface area of the probe to the surface area of the thruster walls ${ }^{13}$ would lead one to believe that a significant perturbation to the discharge should not be expected considering the circumference of the probe is only $1 \%$ of the circumference of the inner and outer walls.
Another method of estimating this loss is by using the measured the ion saturation current over the length of the probe exposed to the plasma. By negatively biasing the tungsten probe we were able to measure this current. This biasing had little effect upon the perturbations induced and comparisons of the ion saturation current to the increase in discharge current. This measurement leads to an ion loss of approximately $70 \mathrm{~mA}$, a factor of ten smaller than the measured changes in the discharge current for the dielectrics; however for the tungsten probe this estimation is quite accurate. Inside of the thruster the ion saturation current and change in discharge current were within $10 \%$ of each other. Outside of the thruster the probe measured the ion saturation current in the plume and did not change the discharge current.

For the ceramic probes the effect of SEE can cause changes in the electron temperature. ${ }^{1}$ This effect can be seen in the measured stationary probe voltages. For xenon, the floating potential on the stationary probe, $\phi_{\mathrm{f}}$, is related to the plasma potential, $\phi_{\mathrm{p}}$, and the electron temperature $\mathrm{T}_{\mathrm{e}}$ by $\phi_{f}=\phi_{p}-5.27 T_{e},{ }^{13}$ and a decrease in the electron temperature of 5 to $6 \mathrm{eV}$ would correspond to the large increases of the stationary probe potential, figure $10 \mathrm{a}$, measured as the probe is inserted. Recent SEE measurements at the PPPL for fused quartz and boron nitride show that at low energies quartz has higher SEE than boron nitride. The first SEE threshold for alumina is at about $25 \mathrm{eV}^{9}$ depending on the purity and for boron nitride is about $29 \mathrm{eV}^{14}$. This would mean quartz has comparable SEE to alumina at low energies. This is consistent with the similar disturbances to the stationary probes caused by the ceramics. The temperature decrease by the probe is localized since on the opposite side of the thruster fig $10 \mathrm{~b}$ the change in the stationary probe voltage is less significant. This temperature loss is also consistent with the emissive probe causing perturbations sooner since cold electrons from the emissive tip of the probe could decrease $T_{e}$ in the same way as SEE and the tip enters the thruster sooner.

For the tungsten probe the SEE is lower than for ceramics ${ }^{15}$ and no such decrease in $\mathrm{T}_{\mathrm{e}}$ would take place. For the tungsten probe the measured 
changes in the stationary probe are probably changes in the plasma potential. This shifting may be related to the conductive properties of the probe in a manner similar to conducting segmented electrodes. ${ }^{12}$ When the tungsten probe is floating the local net current is not zero, only the net current integrated over the length of the probe is zero. In these experiment $60 \mathrm{~mm}$ of the probe was exposed to the plasma. When inside the thruster there was as much as a 200volt change in the plasma potential over the length of the exposed probe. The probe floats at a voltage between that required for local zero current at the high voltage end and that required for local zero current at the low voltage end. The end of the probe seeing higher potentials will mainly collect ions since it is biased slightly negative to the voltage required for local zero current, while the end at low potential will collect both ions and electrons, since it is biased slightly positive to the voltage required for local zero current. The excess of electrons collected at the low potential end of the probe will flow through the conductor to meet and neutralize the ions coming to the high potential end of the probe.

\section{Summary}

We observed two types of discharge current perturbations induced by the probe inserted in Hall thruster, an increase in the discharge current and large amplitude oscillations. Both types are functions of the probe position within the thruster and the material of the inserted probe. It seems that these perturbations are not bulk ablation of the probe material. Additional disturbances due to ablation were attainable but not on the time scale of the probe insertions.

The strong low frequency oscillatory perturbations are induced less than a millisecond after the probe crosses a specific boundary in the thruster while their amplitude can remain almost unchanged for several seconds, fractions of a millimeter downstream of that boundary. The large amplitude oscillations are around $15 \mathrm{kHz}$ and may be ionization instabilities.

The increase in the discharge current perturbation begins outside the thruster and increases to $50 \%$ of the unperturbed discharge current for dielectric probe. Plasma probe interactions taking into account a decrease in the plasma electron temperature due to the SEE and presence of the probe are consistent with the measured changes to the plasma. The increase in discharge current may be due to plasma probe interaction that depends on SEE of the probe material.

The tungsten probe caused very little increase in discharge current about $5 \%$, though it did cause oscillations. The tungsten probe does not have the ablation or other thermally associated problems due to its thermal conductivity and low SEE for typical electron temperatures in the Hall thruster.

The effects of the probes upon the plasma potentials and electron temperature within the thruster are seen to be very similar to the effects of segmented electrodes and changes in the channel wall material.

It is suggested here that in order to avoid large increases in discharge current the insulator of the probes should be completely shielded by tungsten or a similar material with high melting temperature and low secondary electron emission. Operating the thruster at low densities may also reduce perturbations by the probe due to less plasma probe interaction.

\section{Acknowledgements}

Grants from the DOE under contract No. DEAC02-76CHO3073 supported this work.

\section{References}

\footnotetext{
${ }^{1}$ A. Morosov, V. Savelyev, "Fundamentals of Stationary Plamsa Thruster Theory", Review of Plasma Physics, edited by B. Kadomtsev and V. Shafranov, Consultants Breau, New York, 2000, Vol. 21.

${ }^{2}$ Y. Raitses, M. Keidar, D. Staack, N. Fisch, "Effect of segmented electrodes on Hall Thruster plasma", Submitted to Physics of Plasmas, 2002.

${ }^{3}$ E. Chesta, C. lam, N. Meezan, D. Schmidt, M. Cappelli, "A Characterization of Plasma Fluctuations within a Hall Discharge", IEEE Transactions of Plasma Science, Vol. 29, No. 4, August 2001.

${ }^{4}$ J. M. Haas and A. D. Gallimore, "Development of a high-speed, reciprocating electrostatic probe system for Hall thruster interrogation", Review of Scientific Instruments, Vol. 71, Nov. 2000.
} 
${ }^{5}$ W. Hargus, M. Cappelli, "Interior and Exterior Laser-Induced Fluorescence and Plasma Measurements within a Hall Thruster", Journal of Propulsion and Power, Vol. 18, No. 1, JanuaryFebruary 2002.

${ }^{6}$ N.J. Fisch, Y. Raitses, L.A. Dorf, and A. Litvak, "Design and Operation of a Hall Thruster with Segmented Electrode", AIAA 99-2572, Los Angeles, CA, June 1999.

${ }^{7}$ Y. Raitses, L.A. Dorf, A. Litvak, and N. Fisch, Journal Applied Physics, Vol. 89, 2001, p. 2040.

${ }^{8}$ V. Sizonenko, "Effects of strong secondary electron emission on a plasma layer", Sov. Phys. Tech. Phys., Vol. 26, 1345 (1981).

${ }^{9}$ Dawson, "Secondary Electron Emission Yields of Some Ceramics", Journal of Applied Physics, Vol. 37 (9), 3644, 1966.

${ }^{10}$ E. Wang, N. Hershkowitz, D. Diebold, T. Intrator, R. Majeski, H. Pershing, "Secondary Electron Emission-Capacitive probe for plasma potential measurements in plasmas with hot electrons", Journal of Applied Physics, Vol. 61 (10), May 1987.

${ }^{11}$ J.P. Boeuf and L. Garrigues, Journal of Applied Physics, Vol. 84, 1998.

${ }^{12}$ Y. Raitses, D. Staack, N. Fisch, "Plasma Characterization of Hall Thruster with Active and Passive Segmented Electrodes", AIAA 2002- 3954, $38^{\text {th }}$ Joint Propulsion Conference, Indianapolis, IN, 2002.

${ }^{13}$ Hershkowitz, N., "Theory of Electrostatic Probes", Plasma Diagnostics, Edited by O. Auicello, D. Flam, Academic Press, NY, 1989.

${ }^{14}$ J.P. Bugeat, C. Koppel, "Development of a Second Generation of SPT", IEPC-95-35.

${ }^{15}$ A. Ahearn, Physics Review, 38, 1931. 


\section{External Distribution}

Plasma Research Laboratory, Australian National University, Australia

Professor I.R. Jones, Flinders University, Australia

Professor João Canalle, Instituto de Fisica DEQ/IF - UERJ, Brazil

Mr. Gerson O. Ludwig, Instituto Nacional de Pesquisas, Brazil

Dr. P.H. Sakanaka, Instituto Fisica, Brazil

The Librarian, Culham Laboratory, England

Library, R61, Rutherford Appleton Laboratory, England

Mrs. S.A. Hutchinson, JET Library, England

Professor M.N. Bussac, Ecole Polytechnique, France

Librarian, Max-Planck-Institut für Plasmaphysik, Germany

Jolan Moldvai, Reports Library, MTA KFKI-ATKI, Hungary

Dr. P. Kaw, Institute for Plasma Research, India

Ms. P.J. Pathak, Librarian, Insitute for Plasma Research, India

Ms. Clelia De Palo, Associazione EURATOM-ENEA, Italy

Dr. G. Grosso, Instituto di Fisica del Plasma, Italy

Librarian, Naka Fusion Research Establishment, JAERI, Japan

Library, Plasma Physics Laboratory, Kyoto University, Japan

Research Information Center, National Institute for Fusion Science, Japan

Dr. O. Mitarai, Kyushu Tokai University, Japan

Library, Academia Sinica, Institute of Plasma Physics, People's Republic of China

Shih-Tung Tsai, Institute of Physics, Chinese Academy of Sciences, People's Republic of China

Dr. S. Mirnov, TRINITI, Troitsk, Russian Federation, Russia

Dr. V.S. Strelkov, Kurchatov Institute, Russian Federation, Russia

Professor Peter Lukac, Katedra Fyziky Plazmy MFF UK, Mlynska dolina F-2, Komenskeho Univerzita, SK-842 15 Bratislava, Slovakia

Dr. G.S. Lee, Korea Basic Science Institute, South Korea

Mr. Dennis Bruggink, Fusion Library, University of Wisconsin, USA

Institute for Plasma Research, University of Maryland, USA

Librarian, Fusion Energy Division, Oak Ridge National Laboratory, USA

Librarian, Institute of Fusion Studies, University of Texas, USA

Librarian, Magnetic Fusion Program, Lawrence Livermore National Laboratory, USA

Library, General Atomics, USA

Plasma Physics Group, Fusion Energy Research Program, University of California at San Diego, USA

Plasma Physics Library, Columbia University, USA

Alkesh Punjabi, Center for Fusion Research and Training, Hampton University, USA

Dr. W.M. Stacey, Fusion Research Center, Georgia Institute of Technology, USA

Dr. John Willis, U.S. Department of Energy, Office of Fusion Energy Sciences, USA

Mr. Paul H. Wright, Indianapolis, Indiana, USA 
The Princeton Plasma Physics Laboratory is operated by Princeton University under contract with the U.S. Department of Energy.

\author{
Information Services \\ Princeton Plasma Physics Laboratory \\ P.O. Box 451 \\ Princeton, NJ 08543
}

Phone: 609-243-2750

Fax: 609-243-2751

e-mail: pppl_info@pppl.gov

Internet Address: http://www.pppl.gov 